\title{
Pelvic antropometric measurement in 3D CT for placement of two unilateral iliosacral S1 - $7.3 \mathrm{~mm}$ screws
}

\author{
Arnold J. Suda ${ }^{1,2}\left(\mathbb{D} \cdot\right.$ Lisa Helm ${ }^{2,3} \cdot$ Udo Obertacke $^{2}$ \\ Received: 20 December 2020 / Accepted: 24 May 2021 / Published online: 8 June 2021 \\ (c) The Author(s) 2021
}

\begin{abstract}
Purpose Stability of the dorsal pelvic ring is important for patient mobilisation and can be restored using several surgical procedures after fracture. Placement of percutaneous iliosacral screws is a reliable and minimal-invasive technique to achieve stabilisation of the dorsal pelvic ring by placement of two screws in the first sacral vertebra. Aim of this study was to evaluate 3D CT scans regarding the anatomical possibility to place two $7.3 \mathrm{~mm}$ iliosacral screws for fixation of the dorsal pelvic ring. Methods 3D CT datasets of 500 consecutive trauma patients with 1000 hemipelves of a mid-european level I trauma centre with or without pelvic injury were evaluated and measured bilaterally in this retrospective study.

Results One thousand hemipelvic datasets of 500 patients (157 females, 343 males) with a mean age of 49.7 years (18 to 95) were included in this study. Only 16 hemipelves $(1.6 \%, 11$ in females, 5 in males $)$ in 14 patients $(2.8 \%, 9$ females $=5.73 \%, 5$ males $=1.5 \%$ ) showed too narrow corridors so that $7.3 \mathrm{~mm}$ screw placement would not be possible $(p=0.001)$. In women, too narrow corridors occurred 3.9 times as often as in men. Only two females showed this bilaterally.

Conclusion The evaluation of 3D CT scans of the pelvis showed the importance of planning iliosacral screw placement, especially if two $7.3 \mathrm{~mm}$ screws are intended to be placed in the first sacral vertebra.
\end{abstract}

Keywords Pelvis fractures $\cdot \mathrm{S} 1$ —screws $\cdot$ Unilateral screws $\cdot$ Measurement

\section{Introduction}

An intact dorsal pelvic ring is mandatory for human's mobility with upright gait because of force transmission from spine, sacrum, iliosacral joints, and ilium to hip joints and lower extremities. Interruptions of the dorsal pelvic ring caused by fractures lead to severe pain and disability [1]. Previous studies have described safe corridors for iliosacral screw placemen [2-8]. Malpositioning of percutaneous

Arnold J. Suda

arnold.suda@auva.at

1 Department of Orthopaedics and Trauma Surgery, AUVA Trauma Center Salzburg, Academic Teaching Hospital of Paracelsus Medical University, Dr. Franz-Rehrl-Platz 5, 5010 Salzburg, Austria

2 Department of Orthopaedics and Trauma Surgery, Medical Faculty Mannheim of Heidelberg University, University Medical Center Mannheim, Theodor-Kutzer-Ufer 1-3, 68167 Mannheim, Germany

3 Department of Trauma and Orthopaedic Surgery, Asklepios Klinik Nord - Heideberg, Tangstedter Landstrasse 400, 22417 Hamburg, Germany screws remains a problem and can cause iatrogenic nerve injury or revision surgery $[9,10]$. Flouroscopy in the emergency department includes one plain pelvic x-ray [11]. Diagnosis with this imaging is possible but not suitable for correct diagnosis and classifications or pre-operative planning. Further x-rays as inlet- or outlet-view are possible but 3D CT scan is gold-standard for these injuries [11, 12].

Several general pelvic-ring injury classifications have been introduced; the AO/OTA-classification and YoungBurgess classification are commonly used emphasizing on the dorsal ring injury as dorsal stability is clinically impor$\operatorname{tant}[13,14]$.

In definitive care, anatomical reduction and reconstruction should be achieved using external and/or internal stabilization. Unstable dorsal pelvic ring injuries should not be fixed with anterior external fixation only because of insufficient stability $[15,16]$.

Percutaneous screw fixation has low complication rates and small soft tissue trauma.

With CT-based navigation, a significant reduction of malpositioning could be achieved [12, 17-20]. 
Two unilateral iliosacral screws perpendicular to the fracture line in the first sacral vertebra S1 reach the highest stiffness rates whereas one screw provides clinical sufficient stability [21-28]. Use of unilateral $7.3 \mathrm{~mm}$ cannulated screws is one option for fixation.

Biomechanical investigations showed that two unilateral screws in $\mathrm{S} 1$ generate less cut-out and allow more load cycles in the finite-element model [15, 29] and have less risk of neurological injury compared to screws in S2 [25, 30-34].

The aim of this retrospective study was to evaluate sacral S1 corridors in 1000 3D CT datasets to ensure pre-operative planning of unilateral double S1 iliosacral $7.3 \mathrm{~mm}$ screws with distance of $5 \mathrm{~mm}$ each in all patients independent of gender.

Following statements were hypothesized:

- The pelvic $\mathrm{S} 1$ - canal is narrower in women

- The narrowest part of sacral S1 - circle surface in sagittal view in CT-scan is suitable for positioning of two $7.3 \mathrm{~mm}$ iliosacral screws with distance of $5 \mathrm{~mm}$ in all patients.

To our knowledge, no other study has been published to evaluate this high number of measurements regarding gender-specific differences of unilateral positioning of two $7.3 \mathrm{~mm}$ iliosacral $\mathrm{S} 1$ screws.

\section{Methods}

The investigation was performed at the University Medical Center Mannheim, Medical Faculty Mannheim of Heidelberg University, Department of Orthopaedics and Trauma Surgery. After positive regional and institutional ethical committee vote (2016-870R-MA), bilateral evaluation and measurements of the 3D CT scan datasets of 500 consecutive trauma patients with datasets of 1000 hemipelves without pelvic trauma were performed by one single board-certified orthopaedic surgeon and validated by one board-certified radiologist. A mean measured value was calculated of the independent measurements of both investigators. Patients between 18 and 99 years of age were included in this study; patients with osteoporosis, healed pelvic or spinal injuries were not excluded. Patients with pelvic injuries or pathologies as tumors, the presence of implants, or anatomical disorders as lumbalization were excluded. The 3D CT scans were performed using a Siemens Somatom Sensation 16-slice multi-detection scanner using a $3 \mathrm{~mm}$ slice thickness. Measurements were carried out using the OsiriX DICOM Viewer (Pixmeo SARL, Switzerland) using one certified monitor. The following measurements were performed:

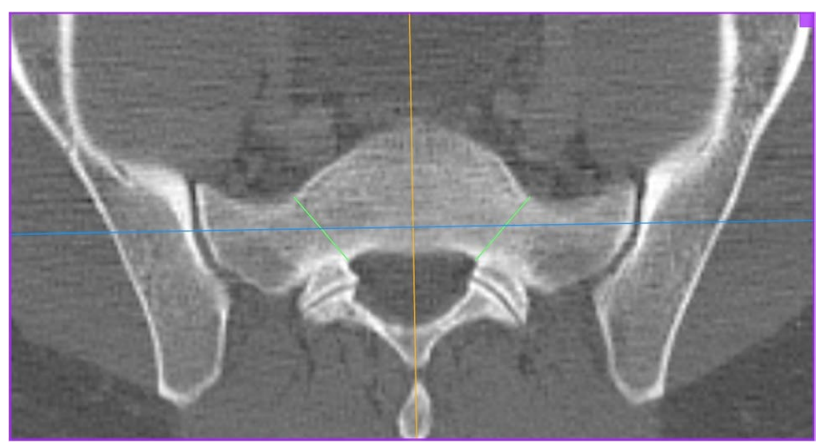

Fig. 1 First sacral vertebral body in axial view

1. The narrowest part of the corridor from ala to corpus between foramen and anterior cortex, $0.4 \mathrm{~mm}$ below upper plate of the first sacral vertebral body in axial view (Fig. 1, green line).

2. The plane of the circle around the narrowest part of the corridor from ala junction to corpus between cranial and caudal lower and upper plate and anterior cortex in sagittal view on both sides (Fig. 2, green circle).

3. The length of the corridor crossing the narrowest part and the corridor angle parallel the tangent to both dorsal spinal processes at the level of the sacro-iliac joint in the axial view of both sides (Fig. 3, green line and green angle, respectively).

Eight variables were defined and calculated regarding sex (Table 1). Statistical analysis was performed using SPSS (SPSS Statistics for Windows, Version 24.0. Armonk, NY: IBM Corp.).

Hypothesis 1 was tested using Student's $t$ test with unpaired samples. The basis for this test was one quantitative dependent variable, two independent samples, normal distribution, unknown variance of the population, and sample homogeneity of variance. For evaluation of homogeneity of variance, the Levene test was performed. For

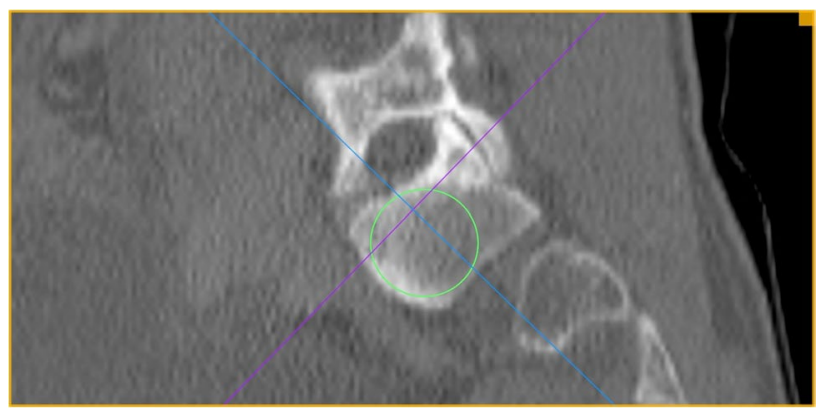

Fig. 2 Cranial, caudal lower and upper plate with anterior cortex in sagittal view on both sides 


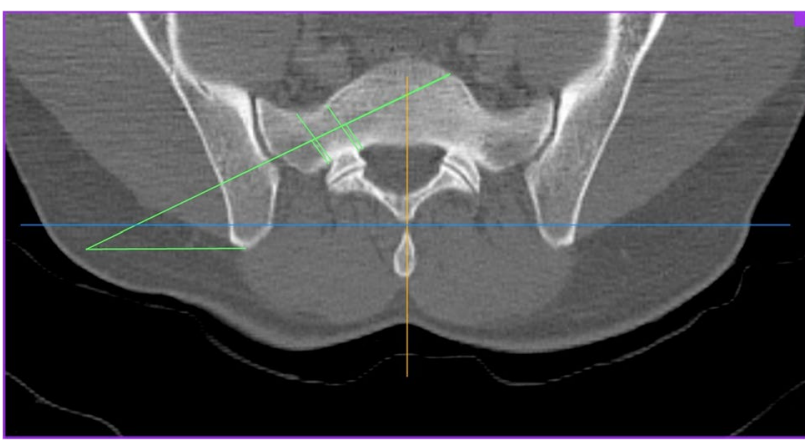

Fig. 3 The level of the sacro-iliac joint in the axial view of both sides

hypothesis 2 , evaluation was performed using single-sample $t$ test because population's variance was unknown and the sample size was $>30$. With this test, significant deviation of mean values to test values was identified. Empiric mean value in this case is arithmetic mean of circle diameters. Test value $(\mu 0=1.96 \mathrm{~cm})$ is the summary of screw diameters and recommended distance between the screws. All subgroups showed variance homogeneity and $t$ test could be performed with normally distributed data.

\section{Results}

Five hundred patients (157 females, 343 males) with a mean age of 49.7 years (18 to 95) at time of investigation were included. The results are presented in Table 1 and show the circle surface of the narrowest part left and right sagittal significantly higher in males.

Canals too narrow for placement of two $7.3 \mathrm{~mm} \mathrm{S1}$ screws were more common in women than in men: $5.7 \%$ of all females, $95 \%$ confidence interval CI: $4-12 \%$ and 5 males $=1.5 \%$ of all males; CI: $0.6-3.4 \% ; p=0.001$.

Regarding the width of the narrowest left axial part, we did not find statistical significant differences between females and males.
In only 16 of 1000 hemipelves $(1.6 \%, 11$ in females, 5 in males) in 14 patients (2.8\%, 9 females, 5 males), it would have been impossible to place two unilateral $7.3 \mathrm{~mm}$ screws with $5 \mathrm{~mm}$ distance to each other in the first sacral vertebra (ration females:males $=3.9: 1$ ). Only two patients showed this restriction bilaterally; in the other 12 cases, we found this unilateral (6 right, 6 left).

\section{Discussion}

In our cohort, $5.7 \%$ of females but only $1.5 \%$ of males showed too narrow corridors for theoretical placement of double ipsilateral $7.3 \mathrm{~mm} \mathrm{S1} \mathrm{screws.} \mathrm{Narrow} \mathrm{corridors} \mathrm{can}$ be easily identified on preoperative CT scan with multiplanar reconstructions.

Except width of the narrowest sacral left axial part, all other parameters showed statistically significant number of narrower canals in females. In $98.4 \%$ of the patients, placement of two unilateral S1 $7.3 \mathrm{~mm}$ screws would have been possible with $5 \mathrm{~mm}$ between the screws. In only 14 patients (16 measurements, 1.6\%), the circle surface diameter was too narrow. We found a ratio of females:males of 3.9:1 for corridors which were too narrow.

Minimal-invasive percutaneous application of iliosacral screws using planar fluoroscopy is gold-standard in surgical treatment of iliosacral injuries. Awareness of anatomical landmarks and surgical technique is mandatory. Van Zwienen et al. showed in a biomechanical study that a second iliosacral screw in $\mathrm{S} 1$ raises rotational stability and load cycles in the finite-element-analysis plus delays failure which supports the rationale of our study [15]. In addition, two screws in $\mathrm{S} 1$ lower the risk of neurological injuries compared to positioning another screw in S2 [21-28, 30-32]. Female sex, advanced age, a high BMI, and previous child birth have previously been associated with narrow $\mathrm{S} 1$ and $\mathrm{S} 2$ canals [2, 35-41].

In our study, a high gauge of repeatability and reproducibility could be achieved through determination of
Table 1 Results of measurements

\begin{tabular}{lrrrrrr}
\hline Variable & \multicolumn{2}{l}{ Values in cm } & & \multirow{2}{*}{$p$ value } \\
\cline { 2 - 5 } & min & $\max$ & mean & SD & \\
\hline Width of the narrowest part right and left axial, females & 0.98 & 15.00 & 1.88 & 0.74 & $<0.01$ \\
Width of the narrowest part right and left, axial, males & 0.50 & 3.14 & 2.04 & 0.40 & \\
Width of the narrowest part left, axial, females & 0.98 & 15.00 & 1.90 & 1.12 & \multirow{2}{*}{0.09} \\
Width of the narrowest part left, axial, males & 0.58 & 3.14 & 2.05 & 0.41 & \\
Height of the narrowest part, saggital, females & 2.09 & 5.36 & 3.42 & 0.70 & $<0.01$ \\
Height of the narrowest part, saggital, males & 2.26 & 6.21 & 4.09 & 0.73 & \\
Circle diameter narrowest part, sagittal, females & 1.60 & 3.85 & 2.43 & 0.29 & $<0.01$ \\
Circle diameter narrowest part, sagittal, males & 1.89 & 5.29 & 2.63 & 0.36 & \\
\hline
\end{tabular}

min minimum, max maximum, $S D$ standard deviation 
landmarks in three planes of the dorsal pelvic ring in addition with the narrowest part of the S1-circle surface in sagittal view.

Our study shows that there are statistically significant gender-related differences in the safe corridors but in $97.2 \%$ of the patients ( $98.4 \%$ of all hemipelves), positioning of two unilateral iliosacral S $1-7.3 \mathrm{~mm}$ screws would have been possible.

Bilaterally narrow corridors were uncommon in our collective: if bilateral $\mathrm{S} 1$ screw-fixation is planned, the risk of encountering a narrow corridor almost doubles.

This study has several limitations:

- First, this was a retrospective study in one single centre with one principal investigator and one validator.

- Second, only mid-European white patients have been included and the ratio of females:males was 1:2.2.

- Third, we did not evaluate information on low body height as risk factor for narrow canals.

- Fourth, with the measurement software used, clinical and intra-operative setting is not equally figured due to different scanners and viewers which could lead to failure or mismatch.

- Fifth, the CT scanner and the slice thickness of $3 \mathrm{~mm}$ are not used by every hospital which could affect the measurement in clinical practice. All measures are only a recommendation for pre-operative planning and support surgical procedure.

In $99 \%$ of male and in $96 \%$ of female hemi-pelvises in this central European cohort, there was enough room to place two $7.3 \mathrm{~mm}$ screws at $5 \mathrm{~mm}$ distance into the $\mathrm{S} 1$ vertebra.

Patients with too narrow corridors can be identified in 3D CT scan preoperatively and therapy can be adapted to anatomical conditions. In a future study, elderly patients with low-energy pelvis trauma will be included to re-evaluate the findings of this study.

\begin{abstract}
Author contribution All authors contributed to the study conception and design. Material preparation, data collection, and analysis were performed by Lisa Helm. The first draft of the manuscript was written by Arnold J Suda and all authors commented on previous versions of the manuscript. All authors read and approved the final manuscript. Conceptualization: Udo Obertacke and Lisa Helm; methodology: Udo Obertacke and Lisa Helm; formal analysis and investigation: Lisa Helm; writing — original draft preparation: Arnold J Suda; writingreview and editing: Arnold J Suda; resources: Arnold J Suda; supervision: Arnold J Suda, Udo Obertacke.
\end{abstract}

Funding Open Access funding enabled and organized by Projekt DEAL.
Data availability With the corresponding author due to ethical committee vote.

\section{Declarations}

Ethics approval The study was approved by the regional and institutional ethical committee (2016-870R-MA) and the authors certify that the study was performed in accordance with the ethical standards as laid down in the 1964 Declaration of Helsinki and its later amendments or comparable ethical standards.

Consent to participate Not applicable due to ethical committee vote.

Consent for publication Not applicable due to ethical committee vote.

Competing interests The authors declare no competing interests.

Open Access This article is licensed under a Creative Commons Attribution 4.0 International License, which permits use, sharing, adaptation, distribution and reproduction in any medium or format, as long as you give appropriate credit to the original author(s) and the source, provide a link to the Creative Commons licence, and indicate if changes were made. The images or other third party material in this article are included in the article's Creative Commons licence, unless indicated otherwise in a credit line to the material. If material is not included in the article's Creative Commons licence and your intended use is not permitted by statutory regulation or exceeds the permitted use, you will need to obtain permission directly from the copyright holder. To view a copy of this licence, visit http://creativecommons.org/licenses/by/4.0/.

\section{References}

1. Rommens PM, Hofmann A (2013) Comprehensive classification of fragility fractures of the pelvic ring: recommendations for surgical treatment. Injury 44:1733-1744. https://doi.org/10.1016/j. injury.2013.06.023

2. Hasenboehler EA, Stahel PF, Williams A, Smith WR, Newman JT, Symonds DL, Morgan SJ (2011) Prevalence of sacral dysmorphia in a prospective trauma population: implications for a "safe" surgical corridor for sacro-iliac screw placement. Patient Saf Surg 5:8. https://doi.org/10.1186/1754-9493-5-8

3. Lucas JF, Routt ML Jr, Eastman JG (2017) A useful preoperative planning technique for transiliac-transsacral screws. J Orthop Trauma 31:e25-e31. https://doi.org/10.1097/bot.0000000000 000708

4. Arlt S, Noser H, Wienke A, Radetzki F, Hofmann GO, Mendel $\mathrm{T}$ (2018) Secure corridor for infraacetabular screws in acetabular fracture fixation-a 3-D radiomorphometric analysis of 124 pelvic CT datasets. J Orthop Surg Res 13:119. https://doi.org/10.1186/ s13018-018-0833-y

5. Blum LE, Hake ME (2018) Preoperative planning for percutaneous transsacral, transiliac screws. J Orthop Trauma 32(Suppl 1):S22-s23. https://doi.org/10.1097/bot.0000000000001196

6. Hwang JS, Reilly MC, Shaath MK, Changoor S, Eastman J, Routt MLC, Sirkin MS, Adams MR (2018) Safe zone quantification of the third sacral segment in normal and dysmorphic sacra. J Orthop Trauma 32:178-182. https://doi.org/10.1097/bot.00000 00000001100

7. Trikha V, Gaba S, Kumar A, Mittal S, Kumar A (2019) Safe corridor for iliosacral and trans-sacral screw placement in Indian 
population: a preliminary CT based anatomical study. J Clin Orthop Trauma 10:427-431. https://doi.org/10.1016/j.jcot.2018. 01.007

8. Wendt H, Gottschling H, Schröder M, Marintschev I, Hofmann GO, Burgkart R, Gras F (2019) Recommendations for iliosacral screw placement in dysmorphic sacrum based on modified in-outin corridors. J Orthop Res 37:689-696. https://doi.org/10.1002/ jor.24199

9. Kim JW, Oh CW, Oh JK, Kyung HS, Park KH, Yoon SD, Yoon SH (2016) The incidence of and factors affecting iliosacral screw loosening in pelvic ring injury. Arch Orthop Trauma Surg 136:921-927. https://doi.org/10.1007/s00402-016-2471-3

10. Maslow J, Collinge CA (2017) Risks to the superior gluteal neurovascular bundle during iliosacral and transsacral screw fixation: a computed tomogram arteriography study. J Orthop Trauma 31:640-643. https://doi.org/10.1097/bot.0000000000000996

11. McAndrew CM, Merriman DJ, Gardner MJ, Ricci WM (2014) Standardized posterior pelvic imaging: use of CT inlet and CT outlet for evaluation and management of pelvic ring injuries. $\mathrm{J}$ Orthop Trauma 28:665-673. https://doi.org/10.1097/bot.00000 00000000127

12. Mendel T, Radetzki F, Wohlrab D, Stock K, Hofmann GO, Noser H (2013) CT-based 3-D visualisation of secure bone corridors and optimal trajectories for sacroiliac screws. Injury 44:957-963. https://doi.org/10.1016/j.injury.2012.11.013

13. Meinberg EG, Agel J, Roberts CS, Karam MD, Kellam JF (2018) Fracture and dislocation classification compendium-2018. J Orthop Trauma 32(Suppl 1):S1-S170. https:// doi.org/10.1097/BOT.0000000000001063

14. Burgess AR, Eastridge BJ, Young JW, Ellison TS, Ellison PS Jr, Poka A, Bathon GH, Brumback RJ (1990) Pelvic ring disruptions: effective classification system and treatment protocols. J Trauma 30:848-856

15. van Zwienen CM, van den Bosch EW, Snijders CJ, Kleinrensink GJ, van Vugt AB (2004) Biomechanical comparison of sacroiliac screw techniques for unstable pelvic ring fractures. J Orthop Trauma 18:589-595. https://doi.org/10.1097/00005131200410000-00002

16. Gansslen A (2010) Biomechanical principles for treatment of osteoporotic fractures of the pelvis. Unfallchirurg 113:272-280. https://doi.org/10.1007/s00113-010-1763-2

17. Takao M, Hamada H, Sakai T, Sugano N (2019) Factors influencing the accuracy of iliosacral screw insertion using 3D fluoroscopic navigation. Arch Orthop Trauma Surg 139:189-195. https://doi.org/10.1007/s00402-018-3055-1

18. Araiza ET, Medda S, Plate JF, Marquez-Lara A, Trammell AP, Aran FS, Lara D, Danelson K, Halvorson JJ, Carroll EA, Pilson HT (2020) Comparing the efficiency, radiation exposure, and accuracy using $\mathrm{C}$-arm versus $\mathrm{O}$-arm with $3 \mathrm{D}$ navigation in placement of transiliac-transsacral and iliosacral screws: a cadaveric study evaluating an early career surgeon. J Orthop Trauma 34:302-306. https://doi.org/10.1097/bot.0000000000 001724

19. Pieske $\mathrm{O}$, Landersdorfer $\mathrm{C}$, Trumm $\mathrm{C}$, Greiner A, Wallmichrath J, Gottschalk O, Rubenbauer B (2015) CT-guided sacroiliac percutaneous screw placement in unstable posterior pelvic ring injuries: accuracy of screw position, injury reduction and complications in 71 patients with 136 screws. Injury 46:333-339. https://doi.org/10.1016/j.injury.2014.11.009

20. Wagner D, Kamer L, Sawaguchi T, Geoff Richards R, Noser H, Uesugi M, Ossendorf C, Rommens PM (2017) Critical dimensions of trans-sacral corridors assessed by 3D CT models: relevance for implant positioning in fractures of the sacrum. J Orthop Res 35:2577-2584. https://doi.org/10.1002/jor.23554

21. Esenkaya I (2002) A morphologic evaluation of the sacroiliac joint and plate fixation on a pelvic model using a S1 pedicular screw, transiliosacral screws, and a compression rod for sacroiliac joint injuries. Acta Orthop Traumatol Turc 36:432-441

22. Osterhoff G, Ossendorf C, Wanner GA, Simmen HP, Werner CM (2011) Percutaneous iliosacral screw fixation in S1 and S2 for posterior pelvic ring injuries: technique and perioperative complications. Arch Orthop Trauma Surg 131:809-813. https:// doi.org/10.1007/s00402-010-1230-0

23. Mendel T, Noser H, Kuervers J, Goehre F, Hofmann GO, Radetzki F (2013) The influence of sacral morphology on the existence of secure S1 and S2 transverse bone corridors for iliosacroiliac screw fixation. Injury 44:1773-1779. https://doi.org/10. 1016/j.injury.2013.08.006

24. Lu C, Song Y, Gao B, Wang G (2014) Parameters of S1 screw fixation for percutaneous screw fixation of the sacroiliac joint using a targeting device: a digital model-based study. Nan Fang Yi Ke Da Xue Xue Bao 34:869-874

25. Salari P, Moed BR, Bledsoe JG (2015) Supplemental S1 fixation for type $\mathrm{C}$ pelvic ring injuries: biomechanical study of a long iliosacral versus a transsacral screw. J Orthop Traumatol 16:293-300. https://doi.org/10.1007/s10195-015-0357-8

26. Goetzen M, Ortner K, Lindtner RA, Schmid R, Blauth M, Krappinger D (2016) A simple approach for the preoperative assessment of sacral morphology for percutaneous SI screw fixation. Arch Orthop Trauma Surg 136:1251-1257. https://doi.org/10. 1007/s00402-016-2528-3

27. König MA, Sundaram RO, Saville P, Jehan S, Boszczyk BM (2016) Anatomical considerations for percutaneous trans iliosacroiliac S1 and S2 screw placement. Eur Spine J 25:18001805. https://doi.org/10.1007/s00586-015-4327-x

28. Dilogo IH, Satria O, Fiolin J (2017) Internal fixation of S1-S3 iliosacral screws and pubic screw as the best configuration for unstable pelvic fracture with unilateral vertical sacral fracture (AO type C1.3). J Orthop Surg (Hong Kong) 25 DOI https:// doi.org/10.1177/2309499017690985

29. van Zwienen CM, van den Bosch EW, Hoek van Dijke GA, Snijders CJ, van Vugt AB (2005) Cyclic loading of sacroiliac screws in Tile C pelvic fractures. J Trauma 58:1029-1034. https://doi.org/10.1097/01.ta.0000158515.58494.11

30. van den Bosch EW, van Zwienen CM, van Vugt AB (2002) Fluoroscopic positioning of sacroiliac screws in 88 patients. J Trauma 53:44-48. https://doi.org/10.1097/00005373-20020 7000-00009

31. Carlson DA, Scheid DK, Maar DC, Baele JR, Kaehr DM (2000) Safe placement of S1 and S2 iliosacral screws: the "vestibule" concept. J Orthop Trauma 14:264-269. https://doi.org/10.1097/ 00005131-200005000-00007

32. Moed BR, Geer BL (2006) S2 iliosacral screw fixation for disruptions of the posterior pelvic ring: a report of 49 cases. J Orthop Trauma 20:378-383. https://doi.org/10.1097/00005131200607000-00002

33. Tabaie SA, Bledsoe JG, Moed BR (2013) Biomechanical comparison of standard iliosacral screw fixation to transsacral locked screw fixation in a type $\mathrm{C}$ zone II pelvic fracture model. J Orthop Trauma 27:521-526. https://doi.org/10.1097/BOT. Ob013e3182781102

34. Crist BD, Pfeiffer FM, Khazzam MS, Kueny RA, Della Rocca GJ, Carson WL (2019) Biomechanical evaluation of location and mode of failure in three screw fixations for a comminuted transforaminal sacral fracture model. J Orthop Translat 16:102111. https://doi.org/10.1016/j.jot.2018.06.005

35. Demir M, Mavi A, Gumusburun E, Bayram M, Gursoy S, Nishio $\mathrm{H}$ (2007) Anatomical variations with joint space measurements on CT. Kobe J Med Sci 53:209-217

36. Gras F, Gottschling H, Schröder M, Marintschev I, Reimers N, Burgkart R (2015) Sex-specific differences of the infraacetabular corridor: a biomorphometric CT-based analysis on a 
database of 523 pelves. Clin Orthop Relat Res 473:361-369. https://doi.org/10.1007/s11999-014-3932-z

37. Balling H (2020) Gender-associated differences in sacral morphology do not affect feasibility rates of transsacral screw insertion. Radioanatomic investigation based on pelvic crosssectional imaging of 200 individuals. Spine (Phila Pa 1976) 45:421-430. https://doi.org/10.1097/brs.0000000000003293

38. Kaiser SP, Gardner MJ, Liu J, Routt ML Jr, Morshed S (2014) Anatomic determinants of sacral dysmorphism and implications for safe iliosacral screw placement. J Bone Joint Surg Am 96:e120. https://doi.org/10.2106/jbjs.M.00895

39. Radetzki F, Wohlrab D, Goehre F, Noser H, Delank KS, Mendel T (2014) Anatomical conditions of the posterior pelvic ring regarding bisegmental transverse sacroiliac screw fixation: a 3D morphometric study of 125 pelvic CT datasets. Arch Orthop Trauma Surg 134:1115-1120. https://doi.org/10.1007/ s00402-014-2022-8
40. Gras F, Hillmann S, Rausch S, Klos K, Hofmann GO, Marintschev I (2015) Biomorphometric analysis of ilio-sacroiliacal corridors for an intra-osseous implant to fix posterior pelvic ring fractures. J Orthop Res 33:254-260. https://doi.org/ 10.1002/jor.22754

41. Wu C, Deng J, Pan J, Li T, Tan L, Yuan D (2020) Anatomical conditions and patient-specific locked navigation templates for transverse sacroiliac screw placement: a retrospective study. J Orthop Surg Res 15:260. https://doi.org/10.1186/s13018-020-01752-0

Publisher's Note Springer Nature remains neutral with regard to jurisdictional claims in published maps and institutional affiliations. 